\title{
DESTRUIR, CONSUMIR, E "INFORMAR": DOS MIL OCHOCIENTOS MILLONES DE SERES INOCENTES
}

\author{
Carmen Rojas \\ A la memoria de Chico Méndez, \\ ejemplo de los desposeídos \\ y grupos autóctonos que detienen, \\ y no causan, el deterioro ambiental.
}

Desde las Naciones unidas nos llega un informe más sobre el ambiente, GEO América latina y el Caribe, perspectivas del medio ambiente, publicado por el Programa de las Naciones unidas para el medio ambiente, producido por el equipo GEO-LAC del PNUMA (Oficina regional para América latina y el Caribe, centros colaboradores regionales y centros asociados regionales) y bajo la dirección editorial del Observatorio del desarrollo de la Universidad de 
Costa Rica (1). Tres instituciones, pagadas con el mismo financiamiento, publican, producen y editan una publicación donde se ofrecen estadísticas actuales sobre el ambiente y nos proponen explicaciones sobre las causas del deterioro ambiental en aumento y perspectivas futuras, con base en fuentes secundarias de información.

EL PNUMA afirma, en dicha publicación: "El contenido de este volumen no refleja necesariamente las opiniones o políticas del PNUMA o de sus organizaciones contribuyentes...", pero entonces iquiénes son los responsables de la siguiente (¡y generalizada!) afirmación, en la página 9, del Resumen ejecutivo?:

"Las dos causas principales de la degradación ambiental en el mundo son la pobreza persistente de la mayoría de los habitantes del planeta y el consumo excesivo por parte de la minoría (UNEP, 1999)".

¿Contará el Programa para el ambiente de las Naciones unidas (UNEP), con estudios científicos recientes de cada país de América latina y el Caribe que constituyan una base de datos confiable, procedentes de la realidad, que fundamentan y llevan en forma contundente a esa afirmación?.

Este análisis no pretende explorar "cuáles son" las causas de la destrucción del ambiente natural sobre la faz de la Tierra, sino más bien reunir casos de la realidad que cuestionen la rigurosidad y veracidad de ciertas afirmaciones que aparecen en informes oficiales ampliamente distribuidos, como la que citamos anteriormente. Aquí radica una de las

1) PNUMA. 2000. GEO América latina y el Caribe Perspectivas del medio ambiente México, ORPALC, y San José, Costa Rica, Observatorio del desarrollo, Universidad de Costa Rica. 144 p. 
tareas más apasionantes de la Academia: analizar la información que llega a nuestras manos y producir nuestro propio conocimiento y crítica.

Volvamos los ojos a la realidad cotidiana con sus ejemplos, que demuestran todo lo contrario a esa afirmación. En el caso de la deforestación del bosque primario en Costa Rica, por ejemplo, por medio del análisis de diferentes tipos de fuentes de información y de observaciones de campo a lo largo de los años, se comprueba cómo las compañías madereras (que no son propiedad de personas pobres) han talado y talan ciertas especies de árboles de enorme valor y tamaño (con costosa maquinaria que sólo ellos pueden adquirir) y que los propietarios (no personas pobres) del transporte, de aserraderos y de fábricas de muebles finos para exportación son los que la comercializan (por ejemplo, Plywood de Costa Rica, S. A., por cuyos portones automáticos entran enormes árboles del bosque primario es propiedad de un poderoso consorcio). Asimismo, son personas con mucho dinero las que pueden adquirir costosos muebles hechos con maderas preciosas provenientes del bosque primario. Finalmente, no son personas pobres las que compran puertas de caobilla y yates enchapados con maderas preciosas de Costa Rica, en los Estados Unidos.

Además, en Costa Rica ya ha sido comprobado por científicos sociales, que las personas sin tierras (debido a la concentración de la mayor parte de la tierra en manos de un pequeño porcentaje de la población), invaden terrenos ya degradados por la ganadería (2), por empresas madereras, o por transnacionales agrícolas. ¿Tienen las Naciones unidas

2) Myers, N. 1981. "The Hamburger Connection: How Central America's forests become North America's hamburgers". Revisea AMBIO 10(1): 3-8. 
documentados los casos (estadísticas y fotos) para cada país en América latina en donde personas pobres hayan invadido un bosque primario, cortando los árboles y haberlos vendido en forma ilegal? ¿Es este un patrón constante?

El desgarrador artículo "The Conquest of NATURE 1492-1992, The Biological Consequences of 1492" (3) nos enseña con casos documentados históricamente, que no son personas pobres las que deterioraron el ambiente, de forma irreversible, en las islas del Caribe. La introducción de especies exóticas como el café, algodón y caña de azúcar por parte de los colonizadores, destruyó casi en su totalidad los bosques nativos en ese lugar.

La historia de Chico Méndez (4): un hecho que nos muestra una comunidad pobre (en el sentido tradicional de pobreza: no tener dinero ni bienes materiales), defendiendo el bosque primario contra ricos empresarios, con poder, que obviamente lo quieren destruir para ganar aún más dinero. La información científica y divulgativa nos dice qué clases sociales (¡económicamente poderosas!) quieren talar los árboles de valor en el Amazonas, empezando por compañías madereras de Malaysia, que seguramente no son propiedad de malayos pobres. La transnacional japonesa Mitsubishi, tampoco propiedad de personas pobres, es el foco de una campaña de RAN (Rainforest Action Network, Red de acción por el bosque lluvioso), por la tala de bosque tropical lluvioso virgen en Asia.

\footnotetext{
3) Report on the Americas, NACLA, NY, vol. XXV, No. 2, Sept. 1991. (La Conquista de la Naturaleza 1492-1992, las consecuencias biológicas de 1492. Informe de las Américas).

4) Cauchero brasileño asesinado por un hacendado ganadero, por defender los bosques de caucho de los que depende su comunidad.
} 
Los pueblos aborígenes son los únicos guardianes de vastos hábitats casi inalterados en lugares remotos en todos los continentes, los cuales albergan gran diversidad biológica. Estas civilizaciones indígenas seguramente caerían en la categoría de personas pobres, según la clasificación de las Naciones unidas, sin embargo, son los que más han protegido y defendido el ambiente natural (5). Los Yanomami y los Kayapo, aborígenes del Amazonas, viven en el bosque y son parte de éste.

Ellos tienen campos de modesto tamaño y siembran cultivos suficientes sólo para sus necesidades. Son los "agricultores" no aborígenes (transnacionales, multinacionales, o inversionistas nacionales) quienes talan el bosque primario, por el que probablemente nunca han caminado, con el fin cubrir el suelo de monocultivos o, como sucedió en los sesentas y setentas, de fincas ganaderas. Lo mejor de esos monocultivos es para exportación, lo de mala calidad, los plaguicidas y los suelos erosionados se quedan aquí. Esto se hace a una gran escala para asegurar que su margen de ganancia les sea satisfactorio, por lo que el impacto en número total de hectáreas es mayor. Un ejemplo de esta destrucción extensiva es la finca de la Volkswagen cuyas quemas se volvieron asunto público sólo cuando fueron vistas desde el espacio por el satélite Skylab (6) ¿Son los dueños de los Volkswagen personas pobres?

En el caso de Centroamérica, existen publicaciones científicas donde se demuestra que la ganadería arrasó con una gran extensión de bosque primario en los setentas e

5) Durning, en Brown, L. et al., 1993, La situación en el mundo. Buenos Aires, Ed. Sudamericana. 402 p.

6) Bourne, 1978, citado por Taylor, en Wilson, E. O., Ed. 1988, Biodiversity. Washington, D. C., National Academy Press. 
inicios de los ochentas. Es muy probable que esas actividades ganaderas no fueron llevadas a cabo por personas pobres, así como la comercialización y transporte de la carne. Habría que ver también quiénes fueron los que consumieron la comida rápida en esos años, si fueron personas del mundo industrializado, o del Tercer mundo. Recordemos una publicación sencilla pero con evidencia científica de Joseph Tosi del Centro Científico Tropical, que compara el aumento de pastizales para ganado con disminución de bosque primario en Costa Rica.

En "El estado del mundo, 1998", publicado por el Instituto de Recursos Mundiales de Estados Unidos, se aclara algunos mitos sobre la deforestación en el mundo:

"...slash-and-burn farmers are often blamed for deforestation for which they are not responsible.

The rising appetite for forest products and trade is a major driving force behind the logging and conversion of many of the world's forests to other uses.

Population growth, however is not the primary cause of rising demand. In fact, most industrial roundwood use takes place in wealthier countries, where population is relatively stable.

... the fuelwood collected by rural households is usually dead wood, which does not contribute to deforestation.

About two thirds of the paper produced worldwide is made from virgin logs; ... Paper consumption is not evenly distributed around the globe. More than 70\% of the world's paper output is used by the 20 percent of the world living in North America, Western Europe, and Japan. In Southeast Asia, the fires ignited regional and global concern... The fires were started by pulp, palm oil, and rubber plantation owners to clear natural forest in Indonesia, 
and then they spread to at least 2 million hectares of forest ... En el Programa para el ambiente de las Naciones unidas deberían nutrirse de este tipo de evidencia científica antes de afirmar (iy publicar!) "Las dos causas principales de la degradación ambiental en el mundo son la pobreza persistente de la mayoría de los habitantes del planeta etc." (7).

¿Son acaso personas pobres, en Estados Unidos y Europa, las que compran las sillas para jardín de $\$ 100$ cada una, hechas con madera de teca nativa de Indonesia, donde ya se agotaron los bosques de teca en las zonas bajas?

¿Qué tipo de metodología, análisis y de trabajo de campo ha realizado las Naciones unidas, de que la pobreza es una de las causas del deterioro ambiental en América latina y el Caribe?, ¿Qué tipo de trabajo de campo realizaron en Costa Rica, por ejemplo, para llegar a tal conclusión?

... los agricultores que practican la roza y quema a menudo son culpados por la deforesración por la que ellos no son responsables.

El apetito en aumento por productos forestales y su comercio es una fuerza importante que priga tras la cala y la conversión de muchos de los bosques del mundo a orros usos. El crecimiento de la poblacion, no obscance no es la causa primaria de la demanda en aumeriso. De hecho, la mayoría del uso industrial de la madera en trozas tiene lugar en parises más ricos, donde la población es relativamente estable.

... la leña colectada por los hogares rurales está hecha de madera muerta, la cual no coneriburye a la deforestación.

Cerca de unos dos tercios del papel producido mundialmente se hace de troncos de bosque virgen: el consumo de papel no esté distribuido uniformemente alrededor del mundo. Más del $70 \%$ de le producción mundial de papel se usa por el $20 \%$ de las personas que siven en Nore América, Europa Occideneal y Japón.

En Asia Sudorienteal, los incendios levantaron interés regional y global... Los incendios fueron iniciados por los dueños de pulpa, palma aceitera y hule para limpiar el bosque natural en Indonesia, y luego se extendieron a al menos 2 millones de hectáreas de bosque ...

Abramovitz, J., 1998. Sustaining the World's Forests. pp. 21-40. In: State of the World. 1998. L. R. Brown, C. Flavin, and H. French. NY, W.W. Norton\& Co., Worldwatch Institute. $251 \mathrm{p}$. 
¿Por medio de qué tipo de mediciones e indicadores se llegó a determinar esa relación de causa-efecto tan específica "POBREZA-DETERIORO AMBIENTAL"?

El informe "Global environmental outlook", también de Naciones unidas (8) defiende abiertamente a la clase más rica de la sociedad y a la economía de apertura de mercados y ataca, directa e indirectamente, a las pobres, ¿repiten también este esquema de razonamiento los equipos que produjeron y editaron el informe GEO América latina y el Caribe (GEO-LAC) porque las Naciones unidas financió la preparación del mismo? En publicaciones recientes hechas en Estados Unidos la tendencia es afirmar que la pobreza y que el aumento de la población en el Tercer mundo son las causas principales del deterioro ambiental, tha cuestionado el Observatorio del desarrollo de la Universidad de Costa Rica (directores editoriales del informe GEO-LAC) esa tendencia, o la aprueban?

¿No cree usted querido lector o querida lectora que esa justificación, diseminada masivamente en casi todas las publicaciones de los países industrializados, es parte de una ideología que trata de justificar, defender, y ante todo mantener, el poder económico de Estados Unidos; el actual nivel de consumo de recursos y energía por parte del mundo industrializado; y la actual distribución de la riqueza en el mundo?

8) En ese informe afirman: "Policy measures to attack this issue must ... Ideally, such measures must simultaneously maintain the living standards of the wealchy, upgrde the living standards of the disadvantaged, and increase sustainability. "Las medidas en el ámbito de políticas para atacar este asunto deben.. Idealmente, tales medidas deben mantener simultáneamente el estándar de vida de los ricos, mejorar la calidad del estándar de vida de los marginados y aumentar la sostenbilidad). UNEP. 1999. Global Environmental Ouilook 1999. Earthscan 
Al producir el informe GEO-LAC, ¿cómo midió/comparó las Naciones unidas:

- El efecto de las actividades productivas de las clases pobres vs. el efecto de las transnacionales (bananeras, mineras, petroleras, madereras);

- El efecto de la ganadería en gran escala;

- El efecto de los latifundios de café, caña, arroz, piña;

- El efecto de la excesiva importación de bienes superfluos, con la excesiva generación de desechos no reciclables; el efecto de la contaminación producida por autos fabricados en el mundo industrializado,

- El efecto de las compañías que explotan tajos;

- $\quad$ El efecto de los gases producto de aire acondicionado y refrigeración de casas y autos; En el deterioro de los ecosistemas naturales, urbanos y agrícolas?

¿Tiene las Naciones unidas y los equipos de trabajo que producen y editan los informes ya mencionados, estudios científicos que demuestren cómo opera la relación causa-efecto, entre la pobreza y la producción, comercialización, y utilización masivas de plaguicidas en el suelo, aire y agua?

En el libro Tropical Rainforest (9) se hace un exhaustivo análisis de las causas de la deforestación en América latina y se menciona la ganadería como la principal causa de destrucción del bosque lluvioso en América latina, ¿cómo explica las Naciones unidas, en el informe recién publicado, este tipo de análisis de Park, con la afirmación de que "la pobreza es la causa del deterioro ambiental", tomando en cuenta que ganaderos, exportadores de carne y consumi-

9) Park, C., 1992. Tropical Rainforest. London, Routledge. 
dores de cortes finos de exportación no son parte de la población de personas pobres?

¿No será más bien que la pobreza, junto con el deterioro ambiental, son consecuencia de la extremadamente enorme y creciente brecha social, del enorme consumo y desperdicio de bienes y servicios en el mundo industrializado; del excesivo consumo de recursos por parte de unos pocos países (Estados Unidos, Singapure y Taiwan); del desproporcionado consumo de energía por parte de Estados Unidos (Estados Unidos ha consumido más energía que la consumida por toda la humanidad desde su presencia en la Tierra (Guerra, 1995); de la excesiva contaminación producida por el mundo industrializado (Estados Unidos es el país que más contamina en el mundo, por ejemplo, consume un $30 \%$ más de oxígeno que el que se produce en su ámbito geográfico); y del pago de la deuda externa por parte de América latina al FM y al BM? (10).

Según el Instituto de recursos mundiales (11) los Estados Unidos fue el país que más consumió energía en todo el mundo (en la forma de combustibles fósiles, sólidos, líquidos y gases) en 1989. Lo mismo para acero, aluminio, cobre, plomo y zinc, para 1990, así como cemento, fertilizantes, madera en tucas, papel y cartón.

La industria de las armas (firmas comerciales de Estados Unidos fueron autorizadas a vender armas en el exterior por

\footnotetext{
10) Véase las cifras de obesidad en Estados Unidos (casi el $55 \%$ de la población sufre sobrepeso, La Nación, 5 de junio del 2000, p. 2-A) y las cifras del consumo de agua y energía en Estados Unidos para cultivar cereales como alimento del ganado, para producir comida rápida en The Earth Works Group. 1993, 50 cosas sencillas para salvar a la Tierra. México, Ed. Diana, S. A. de C. V. 149 p

11) World Resources 1992-1993. State of the World 1993.
} 
un total de $\$ 25.9$ billones de 1989 a 1993 ) y de los cigarrillos, por ejemplo, son industrias millonarias en Estados Unidos que producen, comercializan y exportan para destruir el ambiente iy no son propiedad de personas pobres!. [Según el "Worldwatch Institute", 1998, los guardas privados portadores de armas en Estados Unidos tienen más armas de fuego que las fuerzas policiacas combinadas de los 30 centros urbanos más grandes del país; hay un cuarto de millón de comerciantes de armas con licencia federal, 20 veces el número de restaurantes McDonalds; hay un arma de fuego por cada ciudadano de Estados Unidos desde niños hasta ciudadanos senior; los Estados Unidos es el único país industrializado que permite a sus ciudadanos poseer rifles de asalto tipo militar; más gente es asesinada con armas en Estados Unidos en una semana típica que en toda Europa Occidental en un año; y hay más homicidios en Estados Unidos con armas de fuego en un día que en un año en Japón].

Se gastan $\$ 240$ millones en cigarrillos y $\$ 1500$ millones en armamentos, pero con sólo $\$ 25$ millones por día durante 10 años se podría resolver las muertes de niños por contaminación del agua y las enfermedades graves que padecen los niños por este motivo. El fumado causa en Costa Rica 9 de cada 10 muertes por cáncer del pulmón, 1 de cada 3 cánceres y 8 de cada 10 casos de enfisema. ¿Son acaso personas pobres los dueños de las fábricas de armamentos y de cigarrillos en Estados Unidos y los dueños de las agencias de publicidad que diseñan los anuncios de cigarrillos?

Y puedo agregar, sin temor a equivocaciones, que Estados Unidos es el principal importador de mascotas de especies tropicales, una de las principales causas de la disminución de poblaciones de cientos de especies de fauna silvestre tropical. 
El mundo se ha visto inundado de envases desechables, tipo latas y "tetrabrik", cuyo tiempo de descomposición ni siquiera se conoce, probablemente pasa de los 500 años, ¿son acaso personas pobres los que inventaron, comercializan y compran este tipo de envases?

Las principales fuentes de contaminación del aire (motores de automóvil, refinería de petróleo, industrias químicas, fundición de metales y electrometalurgia, procesamiento de minerales), ¿son acaso propiedad de personas pobres?. ¿Son acaso personas pobres las que están contaminando los mares con petróleo y desechos industriales (metales pesados) y radioactivos? ¿Son personas pobres las propietarias de las industrias (Shell, Dow Chemicals), en Estados Unidos involucradas en la producción y distribución de nemagón, que causó esterilidad de los trabajadores bananeros en Centroamérica? ¿Son personas pobres las propietarias de aviones supersónicos civiles y militares que emiten gases de escape que atacan la capa de ozono?. ¿Son personas pobres las productoras, comercializadoras e importadoras de plaguicidas, que envenenan aproximadamente 30,000 personas en el Tercer mundo? ¿Son personas pobres las que están disminuyendo las poblaciones de tiburón, por medio de la matanza de los mismos y comercialización de su carne? (los dueños de restaurantes pagan $\$ 2,800$ por kilo de aleta y las propietarias de empresas exportadoras ganaron casi $\$ 27$ millones en 1999). ¿Son personas pobres las que están talando el bosque primario tropical en África Central?

Según Bush (1997) (12):

"Los países poderosos pueden tener bajas tasas de natalidad, pero tienen una demanda mucho más alta de recursos

12) Bush, M. 1997. Ecology of a Changing Planet. New Jersey, Prentice Hall, Inc. $434 \mathrm{p}$. 
que cualquier otra nación. Globalmente los Estados Unidos y Canadá tienen las mayores demandas de recursos per cápita que cualquier nación. Si esta demanda es convertida en unidades estándar, se encuentra que el promedio Norteamericano utiliza aproximadamente el doble de los recursos que un británico o alemán o japonés y aproximadamente 400 veces los recursos de un ciudadano de naciones como Rwanda o Etiopía. El nacimiento de un niño en Estados Unidos, pone una carga proporcionalmente mayor en el ambiente que un niño extra en cualquier parte del mundo. Si todas las personas del mundo usaran los recursos a la misma tasa que Norteamérica, habria seria escasez de petróleo, gas, agua, madera y alimentos en solamente unos pocos años. Estados Unidos todavía subsidia sus niveles actuales de consumo importando energía, madera y cosas alimenticias y socavando sus acuíferos. La causa de mucho daño es el apetito por consumo por parte de los países desarrollados".

Una ecóloga, interesantemente de Estados Unidos, llama la atención sobre la insistencia de los científicos del Norte en culpar del deterioro ambiental al crecimiento poblacional del Tercer Mundo. Con base en sus propios análisis matemáticos y estadísticos, menciona cómo el impacto per cápita de $\mathrm{CO} 2$ a partir de fuentes antropogénicas en el Norte (65), es mayor que el impacto del Sur (54), lo mismo para las tasas de nitrógeno aplicado por fertilizantes, aunque en menor grado (impacto per cápita del Norte $=79$, y del Sur $=78$ ). La científica menciona cómo los 24 millones de Estadounidenses que nacieron y se agregan a la población total del país en la última década CONSUMEN MÁS RECURSOS QUE TODA LA POBLACIÓN DE ÁFRICA. Sopesando los parámetros de crecimiento poblacional 
y el efecto per cápita, la autora demuestra que el crecimiento poblacional explica sólo el $39 \%$ del aumento global de CO2 ( $22 \%$ en el Norte, y $17 \%$ en el Sur), concluyendo que el aumento en las emisiones per cápita en el Norte fue la más grande y única fuente del nuevo $\mathrm{CO} 2$ adicionado (13).

Todos los casos juzgados por el Tribunal del agua aquí en Costa Rica, hace unas semanas, se debieron a grandes empresas con el apoyo del Estado (que no es representado por personas pobres) y en ningún caso se trató de "daño ambiental a ecosistemas acuáticos causado por la pobreza", veamos: productores de plantas para exportación, empresa ICA, Banco Mundial, empresa minera HEMCONIC S. A., empresa petrolera ANADARKO PETROLEUM Co. y Basic International Bahamas Resources Ltd., empresa Química Magna S. A., Comisión ejecutiva hidroeléctrica del Río Lempa, empresa Concreto S. A., empresa Unicontal S. A., Moliendas generales S. A. y agregados nacionales S. A. y empresa BERTHIER EBI. ¿Qué pensarían las autoridades que financian las publicaciones sobre el ambiente de las Naciones unidas ante esta realidad?

Las Naciones unidas, con los equipos de trabajo que producen y editan sus informes, nos convence que su lógica institucional es de superficial, injusta y poco rigurosa científicamente al publicar que una de las causas del deterioro de los ecosistemas en el mundo es la pobreza. Las elegantes oficinas de las Naciones unidas casualmente (¿o causalmente?) Están ubicadas en el país más contaminador y más consumidor de la Tierra. Estos informes carecen de análisis históricos, políticos y sociológicos sobre la tenencia de la tierra,

13) Srivastava, D., \& Ruesink, J. L., July 1998, Bulletin of the Ecological Society of America: 219-221. 
que al final, es una de las causas de que haya millones de personas en estado de pobreza.

Los documentos sobre el deterioro ambiental, producidos y publicados en Estados Unidos insistían, hace unos años, en el aumento de la población en el Tercer Mundo como "la causa primaria de la destrucción del ambiente". O si no afirmaban que "los campesinos" ( $\sin$ diferenciar entre agricultura a gran escala de las transnacionales y agricultura en pequeña escala), con su práctica de roza y quema, eran los que estaban destruyendo el bosque lluvioso tropical:

"...Proportionally, however, there is little doubt that farmers are responsible for more deforestation in the tropics than all other factors combined. Farmers account for roughly half of the forest felling in the Third World every year, whereas the lumber industry accounts for approximately one-quarter of forest destruction or degradation annually. In Africa, shifting cultivators are responsible for at least 70 percent of tropical deforestation (14).

Ahora, esta tendencia (¿política?), que se refleja en la diseminación masiva de lo que ellos consideran como las causas del deterioro ambiental, toma un giro y presenta el factor pobreza como causa primaria (!), Aunque continúan en afirmar que "los que tenemos las tasas de crecimiento

14) "...Proporcionalmente, no obstante, existe poca duda de que los agricultores son los responsables por más deforestacion en los trópicos que todos los otros factores combinados. Los agricultores explican más o menos la mitad de la tala de bosque en el Tercer mundo cada año, mientras que la industria maderera explica aproximadamente un cuarto de la destrucción o degradación del bosque anualmente. En África, los que cultivan en forma rotativa son responsables de al menos un $70 \%$ de la deforestación tropical".

Smith et al. 1992. Tropical Forests and their Crops. Ithaca, Comstock Publishing Associates a division of University Press. 568 p. 
poblacional más altas somos los culpables", ubicando el consumismo y desperdicio en los países industrializados (principalmente en Estados Unidos) como causa secundaria y evadiendo a menudo el análisis crítico del mismo.

Finalmente, es bien interesante (y muy cuestionable) notar cómo "el poder" financia, publica y disemina costosas recopilaciones de datos, con el fin de tratar de convencer al mundo de que "la causa de la destrucción de la Naturaleza son los 2,800 millones de seres humanos en estado de pobreza".

Como epílogo, cerramos con un dato curioso: al recibir en forma gratuita el último informe de las Naciones unidas sobre el ambiente, "Global environmental outlook 2000", la factura lo reseñaba como "material publicitario"... 